\title{
Reply to Letter to the Editor: Advanced Age and Success of Bariatric Surgery
}

\author{
Uri Kaplan ${ }^{1}$ (D) Mehran Anvari ${ }^{2,3}$
}

Published online: 29 June 2018

(C) Springer Science+Business Media, LLC, part of Springer Nature 2018

We thank Pontiroli et al. for their interest in our paper. The primary goal of our study was to evaluate the safety of bariatric surgery in the elderly $(>60)$. We found that bariatric surgery in the elderly population is a safe procedure in comparison to the younger one. The higher rate of resolution of obesity-related comorbidities in the elderly advocates bariatric surgery for this age group.

The answer to the question of life prolongation post bariatric surgery is not an easy one. Prospective study may be the best way to answer this question. Recent retrospective publications have shown that bariatric surgery reduces mortality $[1$, 2]. They conducted a case-controlled studies based on retrospective results.

Uri Kaplan

kerenuri@gmail.com

Mehran Anvari

anvari@mcmaster.ca

1 Department of General Surgery B, Emek Medical Center, Afula, Israel

2 Department of Surgery, McMaster University, Hamilton, ON, Canada

3 Division of General Surgery, St. Joseph's Healthcare, Hamilton, ON, Canada
We agree to the fact that the resolution of obesity-related comorbidities should be considered the real index of success of bariatric surgery.

Data Availability Data used in the study were obtained from the Ontario Bariatric Registry (Anvari M., Sharma A., Yusuf S. et al. 2014). The Registry is managed by the Centre for Surgical Invention and Innovation, with analysis and data management provided by the Population Health Research Institute.

\section{Compliance with Ethical Standards}

Conflict of Interest The authors declare that they have no conflicts of interest.

Ethical Statement The study was approved by the Research Ethics Board at the institution where the research was conducted.

Consent Statement Informed consent was obtained from all individual participants included in the study.

\section{References}

1. Reges O, Dicker D, Leibowitz M, et al. Association of bariatric surgery using laparoscopic banding, Roux-en-Y gastric bypass, or laparoscopic sleeve gastrectomy vs usual care obesity management with all-cause mortality. JAMA. 2018;319(3):279-90. https://doi. org/10.1001/jama.2017.20513.

2. Moussa OM, Erridge S, Chidambaram S, et al. Mortality of the severely obese: a population study. Ann Surg. 2018. https://doi.org/ 10.1097/SLA.0000000000002730. 